\title{
SURDOS NA UNIVERSIDADE: \\ QUESTÕES DE LETRAMENTOS, CULTURA E IDENTIDADE
}

\author{
Danielle Cristina Mendes PEREIRA \\ (Universidade Federal do Rio de Janeiro) \\ dcmendes28@gmail.com \\ Valéria Campos MUNIZ \\ (Instituto Nacional de Educação de Surdos) \\ valcammuniz@gmail.com
}

\begin{abstract}
Resumo: Este artigo aborda eventos e práticas de letramento de surdos universitários, a partir de uma visão múltipla de letramento. A presença do surdo no ensino superior exige a tessitura de um novo paradigma de discurso acadêmico, fundamentado em uma percepção fora do logocentrismo, e a ruptura da percepção de letramento como unicamente relacionado ao texto escrito. Desse modo, explanarse-á sobre o afastamento do modelo autônomo de letramento, ao se reconhecer a capacidade e a diversidade das práticas de letramento do aluno surdo, o que implica a compreensão de um indivíduo com potencial de aprendizagem, de modo indistinto do ouvinte, cujo processo de cognição transita por caminhos diversos. A supressão da audição e a condição visuoespacial da Libras orientam um modo de apreensão da realidade fortemente marcado pela visualidade. Assim, busca-se refletir sobre uma lacuna importante no que concerne ao ensino superior de surdos: respeitá-los como falantes de Libras e aceitar seus usos e práticas específicas da Língua Portuguesa, o que pressupõe o reconhecimento de formas desviantes de padrões estabelecidos como únicos e verdadeiros. Propõe-se a reflexão acerca da premência de reconhecer o surdo enquanto membro de um grupo com língua e cultura específicas, respeitando a sua singularidade de participar do mundo por intermédio da Libras, e compreendendo a sua experiência visual, que denota uma maneira peculiar de ver e de estar no mundo, traduzida em determinados comportamentos cognitivos e sociais a perfazer a sua identidade.
\end{abstract}

Palavras-chave: Identidade. Surdez. Letramento. Libras. Língua Portuguesa como L2.

\section{DEAF STUDENTS AT COLLEGE: ISSUES OF LANGUAGE, CULTURE, AND IDENTITY}

\begin{abstract}
This paper discusses literacy events and literacy practices of deaf students in college, based on a multiple vision of literacy. The presence of deaf students in higher education requires the formulation of a new paradigm for academic discourse, based on a perception of literacy that moves away from logocentrism, as well as on the breakdown of literacy perceived as an issue solely related to the written text.
\end{abstract}


Thus, this study will start by denying the autonomous model of literacy as a possible model upon which to frame the education of deaf students. Instead, it will be recognized the ability and the diversity of these student's literacy practices. Moreover, it will be founded on the understanding of the deaf person as an individual with a cognitive potential, just like the student without hearing impairments, but with a cognition process that moves through different paths. The sudent's hearing impairment, on the one side, and the visuospatial condition of Brazilian Sign Language (Libras, in Portuguese), on the other, turn to a reality strongly marked by visuality. Thus, the authors seek to reflect on an important gap regarding higher education for the deaf: their recognition as speakers of Brazilian Sign Language and their specific uses and practices of the Portuguese language. This requires the validation of such uses of the language that might be regarded as deviant uses of norms that are set as unique and true. Moreover, it is necessary to recognize the deaf person as a member of a group with a specific language and culture. Therefore, it is crucial to respect this person's uniqueness to participate in the world through the Brazilian Sign Language and to understand his/her viewing experience, which involves a peculiar way of seeing and being in the world and that is translated into some cognitive and social behaviors, which make up this person's identity.

Keywords: Identity. Deafness. Literacy. Brazilian Sign Language. Portuguese as L2.

\section{Introdução}

Neste trabalho, visamos entender como está instaurada a identidade surda no interior do contexto educacional superior, a fim de desconstruir estereótipos relativos à surdez. Por viver no interior de uma cultura ouvinte, o sujeito surdo, muitas vezes, pode esforçar-se para ser aceito na cultura hegemônica, desconsiderando sua própria identidade e não ocupando um lugar de fato na sociedade, mas um entrelugar, o que trará consequências no seu comportamento social.

A comunidade surda caracteriza-se pela adoção da língua de sinais brasileira (Libras) e a representação de sua identidade em contato com seus semelhantes afasta a noção dominante na cultura ouvinte de que os surdos são incapazes. A concepção do mundo por intermédio da linguagem e das relações sociais e culturais, em determinado contexto histórico, permite a cada ser humano dividir parcelas de sua identidade com os vários grupos sociais nos quais se encontra inserido e com os quais se identifica. A comparação deve ocorrer em meio aos pares. O julgamento de uma cultura em face de outra ocorre em meio às relações de poder e, no caso da 
surdez, no seio de uma cultura ouvinte, hegemônica, cujo olhar para alteridade jamais será neutro.

Quando se rotula o surdo de deficiente, sob a áurea da incapacidade e da anormalidade, subtrai-se desse sujeito a parcela de sua identidade que é comum a outras pessoas. A representação de sua subjetividade encontra-se

\footnotetext{
determinada pelos olhares dos outros, construída em lugares e em tempos sócio-ideológicos distintos e, portanto, um evento plural marcado discursivamente: o eu que se completa, dialogicamente, na (s) relação (ões) com o(s) outro (s) e que se deixa transparecer pela e na linguagem (LODI, 2006, p.200).
}

Em um mundo multicultural, com várias culturas e línguas, a diferença se revela inerente à condição humana. No entanto, é comum o surgimento de conceitos de exclusão e de desigualdade, produzidos no interior de contextos sociais, políticos e culturais, os quais subtraem as diferenças como estratégia para que haja a dominação de certos grupos.

Reconhecer o surdo enquanto grupo com língua e cultura específicas é respeitá-lo em sua singularidade de participar do mundo por intermédio da Libras. É compreender a sua experiência visual, que denota uma maneira peculiar de ver e de estar no mundo, traduzida em determinados comportamentos cognitivos e sociais, que perfazem a sua identidade. Não se pode conferir espaço à cultura surda em contrapartida à cultura ouvinte, pois, conforme já dito, são diferentes formas de estar no mundo. Vê-la a partir desse prisma é destituí-la de sua grandeza para inseri-la num foco minoritário de assujeitamento em franca desvantagem.

Nos discursos sobre a surdez, revela-se ser importante compreender a condição identitária do surdo, de modo a se elaborar uma nova percepção, que fuja da visão do paradigma clínico, da deficiência, para um olhar que perceba o outro como diverso, detentor de uma modalidade linguística visuoespacial, que reflete valores culturais e sociais, bem como atitudes, distintos da cultura ouvinte. O modo particular de socialização do surdo e o uso da língua de sinais demarcam a cultura surda, que, durante muito tempo e ainda hoje, é vista, de modo geral, sob o estereótipo de uma subcultura, a partir de um olhar marcadamente ideológico e pautado em uma percepção clínica, que a assume como condição patológica a exigir "normalização". 
A luta da comunidade surda pelo reconhecimento de sua cultura e pela afirmação de um espaço social que a legitime deflagrou grandes transformações no processo educativo, cujo discurso se distanciou dos critérios de "normalização", instituídos pela visão clínica, em direção a uma educação bilíngue. Mesmo assim, apesar desse avanço, ainda existem muitos entraves pedagógicos, que vão desde as fragilidades das políticas públicas até a precariedade da infraestrutura e, até mesmo, a resistência e a ignorância em relação à Libras e à cultura e identidade surdas, por parte dos envolvidos nos processos educacionais.

Num ambiente de heteroglossia, a abordagem da educação do surdo como bilíngue motivou novas representações no movimento de resistência desse grupo em prol do reconhecimento de sua língua, Libras, como língua materna e primeira língua. Essa conquista imprimiu um resgate linguístico-educacional na contramão do discurso universalizante e monolíngue da cultura ouvinte.

O bilinguismo não significou apenas mudança metodológica, mas também ideológica, com definição de novos espaços artístico e cultural, o que possibilitou o reconhecimento de características cognitivas, linguísticas, sociológicas, educacionais e éticas de um grupo silenciado por muitos e muitos anos. A despeito dos avanços constituídos por esse outro espaço discursivo, o do ensino bilíngue, percebe-se na prática como a educação inclusiva ainda encontra muitos entraves, seja em escolas públicas, onde muitas vezes a falta de um intérprete ou, justamente, só a sua presença não garantem o aprendizado; e como, também, nas escolas especiais, muitas vezes, há o privilégio total do uso e da aprendizagem de Libras em detrimento da língua portuguesa, numa espécie de monolinguismo, às avessas ${ }^{1}$.

Trabalhar no viés do bilinguismo significa constituir competência comunicativa nas duas línguas. Libras, como forma de acesso aos conteúdos e ao aprendizado de português como L2, e a Língua Portuguesa, como acesso ao conhecimento do que se produz na sociedade brasileira. Fazer a inclusão do aluno surdo em classes regulares, sem professores de Libras, com atendimento educacional especializado (AEE) no contraturno, é conceber o bilinguismo em sentido etimológico - uso de

\footnotetext{
${ }^{1}$ Vale lembrar que a legislação prevê o ensino de Língua Portuguesa ao surdo, ao mesmo tempo em que reconhece Libras como a língua oficial de sua comunidade. Ressaltamos que o aprendizado de língua portuguesa se trata de um direito e não de uma obrigação. Ter acesso a esse direito é um dos instrumentos que garantem a cidadania dos surdos e configura-se como um veículo fundamental de poder, diante de uma sociedade ouvinte que se revela, tantas vezes, opressora e excludente.
} 
duas línguas -, sem atentar para aspectos culturais, cognitivos e metodológicos condicionantes do seu processo de aprendizado. Essa pseudoinclusão desconsidera a condição linguística do surdo, tornando sua educação, muitas vezes, "menor", em razão de um contentamento diante de pequenos progressos do aluno, em que o pouco apreendido, "basta".

O conceito de educação inclusiva surgiu com a Declaração de Salamanca, em 1994, que advogava a inclusão das crianças em classes regulares de ensino, em defesa da não segregação em virtude de algum tipo de diferença, sustentada no discurso do direito às diferenças e de uma educação para todos. Há no, entanto, que se verificar qual tipo de inclusão vem ocorrendo de fato, uma vez que a inserção do aluno na sala de aula, por si só, não garante o aprendizado. Aulas de reforço com professor de libras, para a apreensão do conteúdo ministrado no horário regular, somente no contraturno, são contraproducentes, uma vez que não se pode reforçar o que não foi aprendido. O aluno acaba sendo "punido", ao ter de permanecer na escola em outro turno. Como ele é visto, tantas vezes de modo pejorativo, como diferente, existe a necessidade de se compensar essa diferença. Na realidade, essa prática ampara-se em uma visão do surdo como deficiente e a perpetua ao tratá-lo como "anormal", como aquele que necessita de apoio extra, sendo ele o único responsável pelo seu fracasso escolar.

\section{Conforme Sá,}

a escola inclusiva, que está sendo proposta, é uma escola para TODOS desde que todos sejam semelhantes nas suas demandas, ou seja, a chamada "escola inclusiva", da forma que vem sido colocada no Brasil, é uma proposta que esconde que não considera os diferentes (SÁ, 2011, p.18).

Na legislação, verificam-se as diretrizes para a educação especial na educação básica, Parecer CNE/CEB 17/01, que propõem repensar o sistema de ensino, deslocando o foco do problema do aluno para a escola, repousando em dois grandes eixos: o da organização do ensino para o atendimento ao aluno e o da formação do professor. Além delas, a lei 1072/01, trata da educação continuada dos professores, que deverão ter especialização adequada; e, ainda, a Constituição Federal, em seu artigo 208, título VIII, "Da ordem social”, sinaliza o acesso ao ensino obrigatório e gratuito como direito público e subjetivo. Percebe-se, portanto, pela legislação, uma série de direitos assegurados aos cidadãos surdos. É fato a incongruência com a realidade nas salas de aula, uma vez que os direitos não se 
sustentam plenamente, mas isso não desmerece ou invalida os pontos acordados em sua redação, que se configuram como objetivos ainda a ser alcançados.

O discurso da inclusão, portanto, advoga um espaço de convivência comum entre ouvintes e surdos, e choca-se com um sistema educacional, em geral, despreparado para receber o aluno surdo, sustentado por um discurso mantenedor da desigualdade, que mascara a diferença em nome da diversidade.

Conforme Skliar (1997), o conceito de diversidade, quando trazido para o interior da escola, camufla um processo de assimilação da cultura ouvintista, uma vez que um dos maiores contrassensos na educação dos surdos é o fato de docentes e discentes não compartilharem da mesma língua, havendo uma "ambiguidade que dá origem a um poder linguístico indiscutível dos professores e um processo de des-linguagem e de des-educação nos alunos” (SKLIAR, 1997, p. $50)$.

Embora no documento publicado pelo MEC/SECADI haja a indicação de que "a educação bilíngue é regular, em Libras, e integra as línguas envolvidas em seu currículo e não faz parte do atendimento educacional especializado" (BRASIL, 2014, p.6), é comum o aluno surdo chegar à escola sem o domínio de Libras e de língua portuguesa, encontrando dificuldades severas de aprendizado, pois a ausência da língua materna, mediadora dos conteúdos escolares, configura também desafio a ser transposto.

Por mais que o aluno surdo apresente dificuldade na escrita da língua portuguesa, uma vez que o desconhecimento do sistema fonológico impõe um aprendizado visual, é fundamental a percepção da vantagem em seu aprendizado, não como imposição de uma cultura ouvinte, mas como enriquecimento do seu olhar do mundo, de sua trajetória, da conquista de um espaço, em que a língua é fator condicionante de práticas sociais.

Perceber o mundo descortinado pela linguagem é estimular a leitura num ato convidativo, não obrigatório, necessário aos diferentes "eus" existentes em cada um, seja para deleitar-se, para transcender a realidade, para estudar ou para aprender, sem que uma leitura exclua a outra. O aprendizado da língua materna do surdo será o elemento estruturador de seu pensamento, possibilitando a comunicação e a construção da identidade no contato com o outro, perfazendo um sujeito social. $O$ acesso à Libras, consequentemente, é o meio para a estruturação de sua 
subjetividade, de sua inserção no mundo e, principalmente, como veículo de aprendizado, uma vez que a palavra escrita para o surdo é apenas um desenho, que necessita ser explicitado para que haja a conexão: imagem (como significante), significado e referente. Esse processamento imagético do significado demanda esforço muito grande, quando não se tem acesso à estruturação da língua por intermédio da oralidade.

O discurso do surdo como participante de uma minoria linguística já o coloca numa situação de desigualdade em relação ao grupo ouvintista, majoritário, usuário da língua padrão. Há nessa visão, um preconceito e uma visão estereotipada da comunidade surda, cujas características pessoais são vistas de modo homogêneo, como se a surdez, por si só, fosse um identificador que dispensa outros qualificativos.

Os surdos, ao longo dos anos, lutaram por seu espaço na comunidade ouvinte, pelo reconhecimento de sua linguagem e de sua cultura num movimento político. Numa sociedade multicultural, como a brasileira, em que há diversidade de culturas dialogando entre si, o ideário de uma sociedade monocultural e monolinguística, mascara uma igualdade em prol de uma convivência harmônica, ressaltando o discurso das minorias como exótico, não atentando ao conteúdo que trazem de suas práticas, de suas múltiplas identidades.

Pensar em cultura significa atentar para um conjunto de práticas, que abarca a forma de se vestir, costumes, linguagem, padrões de pensamento e até valores políticos, sociais e econômicos, os quais são partilhados. A forma de organização de um grupo dentro da sociedade faz com que seus componentes partilhem ideários que movimentam seus passos paralelamente a outros grupos, podendo haver choque de ideias ou não, bem como lutas acaloradas, dependendo do grau de entendimento do espaço que cada um ocupa. Assim, a existência de várias culturas leva, muitas vezes, ao afastamento entre as pessoas, em virtude de intolerâncias. A questão da alteridade coloca-se no reconhecimento do outro como sujeito de direitos, mesmo que diferente. Esse é um dos grandes desafios da modernidade, que atinge aos muitos grupos existentes, entre eles o das pessoas surdas.

O contraponto à epistemologia multicultural revela-se na pseudo-hegemonia da cultura ouvinte sobre a surda. A diferença não deve obscurecer o conceito de igualdade, que não é sinônimo de homogeneidade, mas sugere um ambiente de 
respeito às diferenças sem valores de superioridade ou inferioridade, porém de igualdade às oportunidades.

Com o discurso educacional não poderia ser diferente, uma vez que há de se pensar nas diversas culturas ao se propor um currículo, a fim de afastar a sombra do fracasso escolar. Para tanto, conforme Skliar (1997), deve haver "um consenso acerca das potencialidades educacionais do surdo (...) centrado nas suas especificidades linguísticas, cognitivas, comunitárias, de participação educativa e culturais" (SKLIAR,1997, p.45). Há que se transpor a visão permissiva da cultura ouvinte em relação ao surdo, para a construção de um espaço educacional no qual o surdo seja incorporado ao cotidiano escolar, numa visão multicultural e não de concessão de benesses a uma minoria.

Assim, urge identificar as múltiplas culturas existentes nos espaços escolares, inclusa a surda, e verificar os discursos que as produziram e produzem, de modo a criar uma pedagogia que trabalhe com os vários grupos de forma entrelaçada e não de modo pontual. Trabalhar com um currículo único, sem considerar a multiplicidade de culturas existentes, significa almejar amalgamar as diferenças, num suposto discurso de tratar igual o diferente.

No que concerne, especificamente, ao espaço da universidade como local de educação de direito dos surdos, deve-se considerar, como visto, o fato de que na última década, uma série de políticas públicas de cidadania e de educação foi voltada para a inclusão e veio a contemplar a formação e a cultura dos sujeitos surdos. Além do reconhecimento e da legitimação da Libras (Língua Brasileira de Sinais) como língua pertencente e partilhada pela comunidade surda, a obrigatoriedade do estudo de Libras por parte dos universitários licenciandos, e a oferta de cursos de graduação, tanto de licenciatura como de bacharelado, na área de Letras-Libras fizeram parte deste elenco de avanços importantes previstos pela legislação.

O apoio legal à existência de práticas e espaços acadêmicos voltados para a língua, cultura e identidade surdas, em consonância ao princípio constitucional de isonomia aos cidadãos, como dito, foi principalmente realizado através da Lei 10.436/ 2002 ("Lei de Libras”). Cabe dizer que o reconhecimento oficial de LIBRAS como língua da comunidade surda trouxe grandes avanços, ao mesmo tempo em que apresentou problematizações e limites. 
No que toca às problematizações, podemos percebê-las como derivadas de embates e tensões acerca do reconhecimento da identidade surda, a partir de construções que reivindicam o deslocamento de uma leitura clínica para uma leitura cultural da surdez, no que toca ao reconhecimento do ser surdo; ao mesmo tempo, liga-se ao enfrentamento de um processo contínuo e fluído de negociações e jogos de poder, que se impõe na tessitura de uma série de ações de inclusão e de exclusão, como ocorre a qualquer processo a envolver as formações e (re) ordenações de identidade, em grupos sociais e culturais. A questão da identidade surda engloba a formação de discursos que delineiam a condição do surdo atrelada a um universo cultural no qual a língua é um signo potente para a assunção identitária.

Já os limites podem ser percebidos no espaço que se instaura entre o texto legal e as práticas cotidianas, por ele permeadas geralmente em situações de enfrentamento e de deslocamento, de modo a proceder à manutenção de um status quo previamente elaborado e situado em um processo de contínuo alijamento da alteridade e da diversidade, a partir de uma série de mecanismos de manutenção de controle, que, muitas vezes, driblam as diretrizes oficiais.

Esses são elementos imprescindíveis para pensarmos a condição dos alunos surdos ingressantes em cursos de graduação. Nesse contexto está presente uma série de fatores que se tensionam em torno de relações de poder, de saber e de identidade, e que põem em xeque percepções estabelecidas acerca do que seja o conhecimento acadêmico superior, trazendo à tona o reconhecimento da diversidade cultural e o enfrentamento de preconceitos há muito arraigados.

No que se refere aos cursos presenciais, percebe-se a intensidade desses enfrentamentos, uma vez que a presença física do surdo no espaço universitário implica um redimensionamento importante dessas relações de poder, as quais podem ser lidas a partir de uma série de semioses, como a organização espacial e os modos de gerenciamento da comunicação, por exemplo.

Dentro desse quadro, uma questão que percorre todo esse processo e que demanda investigações são os eventos e as práticas de letramentos em língua portuguesa dos alunos universitários surdos, por todo o contexto que os envolve: o fato de os surdos estarem inseridos em um ambiente multicultural e bilíngue; de serem brasileiros, porém terem a Língua Portuguesa como segunda língua (L2) e 
não como língua materna (L1); o reconhecimento da legitimidade de Libras como língua acadêmica, o que implica, por exemplo, na sua admissão como opção na prova de línguas para o ingresso em cursos de pós-graduação stricto sensu²; a compreensão da extrema importância de intérpretes competentes em sala de aula e, ao mesmo tempo, a consciência de que não basta, apenas, a interpretação, uma vez que os processos de educação que envolvem a questão da surdez são complexos e articulados a outras questões, como a garantia de uma infraestrutura audiovisual e a necessidade de pesquisar metodologias específicas de ensino e de aprendizagem voltadas para alunos surdos.

Todos esses pontos convergem para o questionamento de uma tradição logocêntrica no espaço acadêmico, a qual, notadamente, põe geralmente em primeiro plano a oralidade e a escrita como meios privilegiados de aquisição e de demonstração de conhecimento, dentro do universo do ensino superior. Na situação em tela, a presença do aluno surdo, de sua cultura e identidade, encontram no espaço universitário formas de compreensão do mundo e do saber que passam a ser postas em questionamento, a partir da presença de novos paradigmas de comunicação e de construção do conhecimento e da realidade.

De fato, impõe-se uma situação de enfrentamento de formas culturais distintas na qual se situa a questão do letramento em língua portuguesa para os surdos. Como abordado, o processo de aquisição da Língua Portuguesa dá-se como L2, para os surdos natos e para a maioria dos demais surdos. Estudos, como os empreendidos por Sacks (1998) e Botelho (2002), demonstram como o processo tardio de aquisição de uma língua materna pode interferir na compreensão de outras línguas.

Nesse sentido, Botelho afirma que a aquisição de Libras como L1 para os surdos é fundamental para torná-lo capaz de dominar a Língua Portuguesa; a autora defende, em sua pesquisa, que a imersão de crianças surdas em processos de oralização pode ser disfuncional, sendo mais potente e recomendável para o seu desenvolvimento linguístico a aquisição de Libras como L1. Do mesmo modo, a autora aponta a falência do ensino de língua portuguesa para surdos no Brasil,

\footnotetext{
${ }^{2}$ No segundo semestre de 2014, a Universidade Federal do Rio de Janeiro, em seu exame de seleção para o Doutorado em Letras, admitiu Libras como uma das opções para a prova de idiomas.
} 
mesmo em relação aos que adquiriram desde cedo Libras como língua materna, principalmente, por razões afetivas e psicológicas vinculadas a sentimentos de exclusão e de impotência, assim como por conta do que entende como a mediocridade das escolas surdas e do fato de que muitos professores não possuem uma comunicação efetiva com os alunos, já que não dominariam Libras.

Em um caminho distinto, pretendemos aqui observar os eventos e as práticas de letramento de surdos universitários, a partir de uma percepção da ideia de letramento como um evento social, ligado a contextos específicos, e que revela determinadas práticas e visões da realidade. Assim, buscamos apoio teórico nos Novos Estudos de Letramento e apontamos a validade do modelo ideológico de letramento proposto por Street (2014), a partir da compreensão do aluno surdo como um sujeito envolvido em práticas de letramento plurais e situadas, de modo a apoiarse em uma visão múltipla do letramento, ao reconhecer que o significado e as práticas de letramento são ligados a certos contextos sociais e culturais, estando envolvidos com o modo através do qual são organizadas e estabelecidas relações de poder e de ideologia.

De fato, propomos o afastamento de uma concepção que situe no indivíduo o sucesso ou o fracasso no que toca ao domínio de códigos estabelecidos de leitura e escrita, como padrões únicos, perfeitos e inquestionáveis. Abordamos ações e atividades de pessoas que vivam, pertençam e partilhem as suas experiências em um grupo, significando-as também coletivamente. Tratamos, aqui, de jovens adultos falantes de Libras, que comungam de compromissos e práticas acadêmicas universitárias e fazem uso da língua portuguesa dentro e fora do espaço da sala de aula, sobretudo em redes sociais, em processos de letramento concretos.

Reconhecer a capacidade e a diversidade das práticas de letramento do aluno surdo implica em compreendê-lo como um indivíduo com pleno potencial cognitivo, de modo indistinto do ouvinte, embora o seu processo de cognição possa transitar por caminhos diversos. Entender a especificidade da cognição do surdo é fundamental para empreender a pesquisa e a prática relativa a novas formas de economia do conhecimento, com impactos não só sobre o cotidiano da sala de aula, mas ainda sobre o próprio entendimento acerca do que seja o saber.

A supressão da audição e a condição visuoespacial da Libras (STROBEL, 2006) orientam um modo de apreensão da realidade fortemente marcado pela 
visualidade, sendo possível reconhecer uma hipervisualidade nos indivíduos surdos (SACKS, 1998). As experiências de construção cognitivas amparadas na visualidade vêm se revelando potentes no processo de construção de conhecimento dos surdos e demonstram a sua capacidade de abstração, tantas vezes questionada (SACKS, 1998). Retornamos, aqui, à questão da importância da aquisição da linguagem, pois esta é absolutamente intrínseca à capacidade de categorizar e de abstrair. Ou seja: o surdo possui pleno potencial cognitivo, sendo perfeitamente possível a ele o pensamento abstrato e a habilidade de pensar através de categorias mentais, atrelada àquele. Entretanto, sem a aquisição da linguagem, como aconteceria a qualquer outro indivíduo, tais capacidades tornar-se-iam limitadas.

No que tange especificamente à língua, a construção da sintaxe de Libras e de outras línguas de sinais, Sacks (1998) estabelece processos de representação que partem do espacial e/ou do mais amplo para o mais específico. Isso leva a uma produção discursiva em Libras que tende a uma complexidade narrativa nas estruturas de simbolização dos espaços. A proposição de quaisquer projetos de ensino e de aprendizagem em Libras, incluso os que abarcam os letramentos, não podem prescindir do conhecimento desses aspectos. Do mesmo modo, importa saber que é frequente a transposição das estruturas presentes em Libras para a escrita em Língua Portuguesa por parte dos surdos; por esta razão, a defesa da existência de uma analogia entre o ensino de língua estrangeira para um aluno cuja língua materna seja oral e o ensino de Língua Portuguesa para um aluno surdo deve ser repensada, uma vez que se tratam de línguas com estruturas sem homologia, sendo uma oral e outra visuomotora.

Por conta dessa transposição entre as estruturas de Libras e Língua Portuguesa, muitas vezes, nos deparamos com construções recorrentes na produção de alunos surdos, como, por exemplo, a elisão de conectivos. Em Libras, os conectivos são empregados de modo muito distinto da língua portuguesa, levando, inclusive, ao equívoco de se acreditar que estes não existam naquela língua. $O$ fato de haver tal distinção não significa que uma língua seja mais completa do que a outra, mas aponta, somente, para as suas diferenças, as quais devem ser consideradas. Do mesmo modo, importa compreender o uso da Língua Portuguesa por alunos surdos como uma instância atrelada a formas e práticas específicas e construídas a partir de contextos culturais próprios, profundamente marcados pela 
experiência visuoespacial de Libras, como língua materna, e por modos próprios de cognição. Afastamo-nos, assim, de uma ideia frequente: a do inevitável analfabetismo funcional do surdo, percepção que vinculamos a um olhar marcadamente ideológico do processo de letramento, que o percebe como um modelo autônomo.

O afastamento do modelo autônomo de letramento abre uma senda para a compreensão de modos de letramento presentes nas experiências dos sujeitos surdos. Pensar neles como produtores e consumidores de práticas de letramentos em Língua Portuguesa, em espaços diversos - sobretudo os das mídias sociaispressupõe o reconhecimento de formas desviantes de padrões estabelecidos como únicos e verdadeiros.

No caso dos surdos universitários, no Brasil, o amparo da lei obriga à aceitação de uma escrita em língua portuguesa fora do que se instituiu como o padrão e exige que, nos concursos de acesso às universidades, a correção das redações de surdos leve em conta que os textos são produzidos como L2, considerando nestas produções, sobretudo, a coerência em detrimento à coesão ${ }^{3}$. Isso nos leva a refletir sobre os alcances da legislação inclusiva, pois se por um lado reconhece e aceita as especificidades da escrita de Língua Portuguesa por sujeitos surdos ${ }^{4}$, por outro não garante que estas sejam respeitadas dentro do próprio espaço universitário, assim como não assegura neste a legitimação de Libras como língua acadêmica. Afirmase, dessa maneira, uma lacuna importante no que toca ao ensino superior de surdos, pois a permanência e o desenvolvimento do aluno surdo no espaço acadêmico não podem prescindir da garantia de que seja reconhecido como falante de Libras, tampouco de seus usos e práticas específicas da Língua Portuguesa. Outro ponto correlato e importante a destacar é a premência da universidade reconhecer as modulações cognitivas dos sujeitos surdos, ancoradas na visualidade, e tanto produzir para estes alunos, como aceitar destes materiais que não suportem apenas o texto escrito.

\footnotetext{
${ }^{3}$ Uma das características mais recorrentes em textos de surdos é a sua construção através de uma tessitura própria, na qual a coesão é estabelecida de modo diverso dos falantes de língua portuguesa, especialmente por causa da elisão de conectivos.

${ }^{4}$ Defender as especificidades da escrita dos surdos não significa assumir uma postura de limite em relação ao permanente aprendizado e domínio da língua portuguesa, mas pontuar a compreensão de um ponto de partida para que esses ocorram, sem, entretanto, deixar de entender a sua ligação a um contexto de L2, para tal grupo.
} 
O quadro supracitado inscreve-se na tensão com modelos de conhecimento universitário consolidados, a partir do momento em que a presença do surdo na universidade exige a tessitura de um novo paradigma de discurso acadêmico, fundamentado em uma percepção fora do logocentrismo, e a ruptura da percepção de letramento como unicamente relacionado ao texto escrito. Para tanto, é fundamental a dupla compreensão do reconhecimento de um discurso acadêmico surdo e dos novos letramentos a ele conexos. Isso implica reconhecer a presença de um letramento dominante (STREET, 2014) no espaço universitário e a fricção existente entre os novos sentidos para o letramento acadêmico, os quais são semeados pela presença física e simbólica dos surdos na Academia, e o status quo por ela defendido. Aponta, ainda, para as fragilidades de um modelo arcaico e as suas maneiras de enfrentar a diversidade, muitas vezes vista como diferença, em um sentido negativo.

Uma série de aparatos culturais, políticos e econômicos vinculam-se e sujeitam-se a formas determinadas de atuação subjetiva e estas são abaladas pela presença da multiplicidade de novos modelos de letramento, que de novos têm apenas o pouco tempo de reconhecimento. Compreender distintos modos, práticas e modelos de letramentos envolve reconhecer que a época na qual se considerava apenas o texto impresso como índice de prática letrada já acabou, como afirma Jewitt (2008), ao postular que o letramento não é mais somente uma realização linguística. Segundo a autora, seria mais coerente falar em "letramentos que se movem para além dos processos cognitivo e analítico da linguagem escrita" (JEWITT, 2008, p.246), uma vez que houve transformações profundas nos modos de comunicação, como lembra Kress, ao demonstrar como o domínio absoluto do texto/escrita passa a ser deslocado para a relação tela/imagem: "essas duas juntas estão produzindo uma revolução nos usos e efeitos do letramento e de meios associados para representação e para comunicação em todos os níveis e domínios" (KRESS APUD JEWITT, 2008, p. 241).

Deste modo, o que aqui defendemos é a percepção de alunos surdos universitários como membros de uma comunidade de práticas que participam de eventos e práticas de letramentos, isto é como:

An aggregate of peoples who come together around mutual engagement in an endeavor. Ways of doing things, ways of talking, values, power relations - in short, practices - emerges in the 
course of this mutual endeavor. As a social construct, a CofP is different from the traditional community, primarily because it is defined simultaneously by its membership and by the practice in which that membership engages (ECKERT \& MCCONNEL-GINNET, 1994, p.490).

Defender esse posicionamento significa assumir que tais estudantes possuem uma maneira específica de compreender e de lidar com as dinâmicas da cultura escrita, a partir da manipulação de práticas e de usos coadunados ao seu universo linguístico e cultural. Reconhecemos, pois, a divergência das formas e práticas escritas produzidas pelos alunos surdos das esperadas pelo padrão acadêmico. Porém, a partir do apoio teórico dos Novos Estudos de Letramento e de uma compreensão dos letramentos através do modelo ideológico, propomos aqui o afastamento do surdo do estigma de iletrado.

As dificuldades em ler textos escritos longos, a escrita com sintaxe fora dos padrões, a elisão de conectivos, a falta de flexão verbal e de desinência de gênero são, sim, recorrentes tanto entre universitários surdos quanto entre surdos em geral. Entretanto, se percebermos os letramentos como múltiplos, se os entendermos como atrelados a contextos variados, como práticas socioculturais e sociolinguísticas, podemos afastar a ideia de um modelo de letramento acadêmico único e superior e propor o reconhecimento, inclusive na universidade, de outras formas legítimas de letramento. Isso requer, também, a compreensão da faceta política desse contexto, como arena mesmo de negociações por espaços de poder e pelas identidades a ele conexas. Reconhecer a pluralidade das práticas letradas e dos contextos sociais aos quais estas se vinculam implica, sobretudo, o questionamento e o enfrentamento desses poderes e dessas identidades.

Por fim, gostaríamos de propor como uma chave essencial para o trabalho e o reconhecimento acadêmico de alunos surdos universitários a reflexão sobre os multiletramentos e o multimodalismo. A compreensão do multiletramento, como forma cognitiva, de expressão e de modelagem de sentidos, e do multimodalismo, como assunção de novos modelos de comunicação, propõem o enfrentamento de práticas baseadas no logocentrismo, a partir do momento em que o meio e o modo pelo qual os processos acadêmicos de ensino e aprendizagem ocorrem implicam a criação e a manipulação de discursos acerca do que é o conhecimento, o que pode tanto ratificar quadros de exclusão como ampliar perspectivas fundamentadas no respeito à diversidade e à diferença, assim como à percepção de novas formas de economia do conhecimento, de letramentos, de relações de poder e de identidade. 
Podemos inferir que a forma de representar está integrada ao significado e à aprendizagem, no que toca aos elos entre os conteúdos curriculares e os modos de aprender. Em relação aos surdos e à sua inserção no ensino superior, cabe sublinhar que a compreensão e o respeito às suas peculiaridades linguísticas e cognitivas, assumem a sua dimensão de sujeitos fortemente marcados pela visualidade e espacialidade, configurando-se a educação multimodal como uma chave relevante também em processos de educação de maior complexidade, como os instaurados pelo ensino superior. A aceitação de uma educação com base no multimodalismo e na intersemiose prevê a reflexão sobre os modos de representação e de comunicação e as suas modulações nos processos de formação, interpretação e (re) ordenação de significados.

Essa postura acadêmica pressupõe a assunção de que a linguagem em sua forma escrita é apenas um dos meios possíveis de representação e de comunicação, o que legitima o reconhecimento de uma produção acadêmica afastada do logocentrismo, ainda profundamente dominante nas universidades brasileiras, e torna possível aceitar outras fontes de produção discursiva, a partir de fontes semióticas múltiplas e perfeitamente capazes de tecerem discursos tão complexos quanto os escritos, ainda que a partir de modos distintos.

Portanto, percebemos como a inserção de alunos surdos no espaço acadêmico proporciona a emergência de novas condições de letramento, as quais impactam conceitos de ensino superior e de aprendizagem distintos do padrão a envolver jogos de poder e de exclusão, mas também de resistência, uma vez que a construção da ideia de Letramento pelas instituições oficiais de ensino nem sempre vai ao encontro das práticas de Letramento emergentes na comunidade dos surdos universitários.

A perspectiva instituída pelos Novos Estudos de Letramento postula uma abordagem social dos Letramentos e permite pensar como as suas práticas sociais são estruturadas e negociadas através de relações específicas de poder, formas de conhecimento e de identidade no contexto universitário, a partir do momento em que se instaura a presença de novos atores, que carregam vivências, identidades e ações de letramento singulares, o que impõe discursos alternativos ao padrão dominante. 
E, como lembra Gee (2000), a mudança na prática discursiva implica a marcação, potencialmente, de uma mudança de identidade, que, se espera, amplie a percepção de mundo para além do padronizado e abra espaço para um quadro de diversidade, no qual se situa o aluno surdo, fora de uma perspectiva política e cultural excludente. Isso significa assumir a existência de identidades, representações e discursos múltiplos nas modulações sociais (SKLIAR, 1998). Assim, pretendemos defender e reconhecer que a legitimidade dos letramentos produzidos pelos surdos universitários vincula-se à desconstrução da relação entre surdez, analfabetismo funcional e limitação cognitiva, a partir da compreensão de sua dimensão política e da pluralidade dos letramentos e dos contextos sociais a eles vinculados.

\section{Referências}

BOTELHO, Paula. Linguagem e Letramento na Educação dos Surdos: ideologias e práticas pedagógicas. Belo Horizonte: Editora Autêntica, 2002.

BRASIL. LEI n.10.436/2002. Disponível em: <http//:planalto.gov.br>. Acesso em: 10 fev. 2015.

ECKERT, Penelope et MCCONNELL-GINET, Sally. Think Practically and Look Locally: Language and Gender as Community-Based Practice. In: The Women and Language Debate. New Brunswick: Rutgers University Press, 1994.

GEE, J. The New Literacy Studies: from "socially situated" to the work of the social. In: BARTON, et alli. Situated Literacies: reading and writing in context. London: Routledge, 2000.

JEWITT, Carey. Multimodality and literacy in school classrooms. In: Review of Research in Education, What Counts as Knowledge in Educational Settings: Disciplinary Knowledge, Assessment, and Curriculum. Vol. 32, 2008. Disponível em: <http://rre.sagepub.com/content/32/1/241.full.pdf>. Acesso em 20 abr. 2015.

LODI, Ana Claudia. A leitura em segunda língua: práticas de linguagem constitutivas da(s) subjetividade(s) de um grupo de surdos adultos (2006). Disponível em <http://www.cedes.unicamp.br>. Acesso em 10 jun. 2015.

SÁ, Nídia Regina Limeira de. Escolas e classes de surdos: opção políticopedagógica legítima. In: SÁ, Nídia Regina Limeira de (org.). Surdos: qual escola? Manaus: Editora Valer e Edua, 2011. 
SACKS, Oliver. Vendo Vozes: uma viagem ao mundo dos surdos. São Paulo: Companhia das Letras, 1998.

SKLIAR, Carlos. A forma visual de entender o mundo. In: Educação para todos. Revista especial, SEED/DEE. Curitiba: Editora Expediente, 1998.

Bilinguismo e biculturalismo: uma análise sobre as narrativas tradicionais na educação de surdos (1997). Disponível em: <http://anped.org.br/rbe/rbedigital/rbde08/rbde08_06_carlos_skliar.pdf>. Acesso em 05 mai. 2015.

STREET, Brian. Letramentos Sociais: abordagens críticas do letramento no desenvolvimento, na etnografia e na educação. São Paulo: Parábola Editorial, 2014.

STROBEL, Karin Lílian. A visão histórica da in (ex) clusão dos surdos nas escolas. In: ETD Educação Temática Digital. Campinas, v.7, n.2, p.245-254, jun. 2006. 
Artigo recebido em: 03 de julho de 2015

Artigo aprovado em: 01 de setembro de 2015

\section{Sobre as autoras:}

Danielle Cristina Mendes Pereira é Mestre em Literatura Brasileira (2001) e Doutora em Literatura Comparada (2006), pela Universidade Federal Fluminense. Tem experiência na área de Letras, com ênfase em Literatura e Vida Cultural; interessa-se, principalmente, pelos seguintes temas: diálogos entre linguagens artísticas; memória e representação literária; ensino de literatura e surdez; letramento literário. Membro (pesquisadora) dos Grupos de Pesquisa Linguagem \& Sociedade (FFP/UERJ-CNPq) e LAPEEL - Laboratório de Pesquisa, Ensino e Extensão da Libras (UFRJ - CNPq), é Professora Adjunta A da Universidade Federal do Rio de Janeiro, na área de Estudos Literários, com atuação no Departamento de Letras/Libras.

Valéria Campos Muniz é Doutora em Língua Portuguesa (2013) e mestre Língua Portuguesa, (1997) pela Universidade do Estado do Rio de Janeiro. Foi bolsista da CAPES durante o Doutorado. Atualmente é professora adjunta de Língua Portuguesa como L2 - 40 horas com dedicação exclusiva - do INES. Tem experiência na área de Letras e atua principalmente nas seguintes áreas: leitura, aquisição da língua escrita, língua portuguesa como L2, gramática e ensino. Foi professora na Universidade Estácio de Sá no curso presencial e a distância, tendo ocupado o cargo de coordenadora do curso de Letras no campus de Nova Friburgo. Membro (pesquisadora) do Grupo de Pesquisa Linguagem \& Sociedade (FFP/UERJCNPq). Possui publicação em anais de eventos nacionais, internacionais, e em revistas. Área de interesse: linguística textual, estudos do letramento e língua portuguesa como L2. 